\title{
Optimization of the freight transportation system within the raw material enterprises
}

\author{
Liudmila Trofimova ${ }^{1, *}$, Tatiana Pantina $^{2}$, Nikolay Pevnev ${ }^{1}$, Svetlana Borodulina ${ }^{2}$, Boris Trofimov ${ }^{1}$ \\ ${ }^{1}$ Siberian State Automobile and Highway University (SibADI), Mira str., 5, Omsk, 644080, Russia \\ ${ }^{2}$ Admiral Makarov State University of Maritime and Inland Shipping, 5/7, Dvinskaya st., St. Petersburg, \\ 198035, Russia
}

\begin{abstract}
The article presents the results of a study to establish the relationship between the planned indicators formed in the operational work of the road transport enterprise when transporting goods and the indicators formed in the current work. The authors consider the functioning of a road transport enterprise in the current mode on the methodological basis of the theory of road freight transport, the theory of rolling stock maintenance, the system approach, using economic and mathematical methods. The criterion for optimising planning is the profit of the road transport company, and the constraints are the output, mileage and labour intensity of maintaining the rolling stock, which depends on the probability values of the length of the ride with freight, the mass of the freight, average technical speed and time for loading and unloading. The application of the developed methods and mathematical model to optimise planning will make it possible to study the functioning of a road transport enterprise as a probabilistic system and to determine planning indicators, considering the influence of random factors that appear in the current and operational work of the road transport enterprise.
\end{abstract}

\section{Introduction}

The relevance of forming theoretical and methodological approaches to optimising the planning of freight road transport enterprises (RTE) is justified by the need to fulfil the conditions of customers' contracts in the operational mode, which involves the transportation of goods daily (urban transport) and monthly (intercity transport). The main purpose of current planning is to set targets for freight transport, maintenance and repair operations (MRO) on a quarterly and annual basis. The development of plans that correspond to the actual transport process of goods transport and the performance of MRO will ensure the fulfilment of contractual conditions and the generation of profit. The current small business environment in Russia is favourable for the operation of road transport enterprises (RTE). Today, there is a need to develop a new theoretical and methodological approach that makes it possible to propose a mathematical model and planning methods for RTE practices in operational and current modes, considering the impact of probabilistic factors on freight transportation and maintenance and repair operations.

\section{Materials and methods}

The paper [1] substantiates the timing of freight transport as a planning optimisation constraint, allowing the authors to establish a relationship between the static and online paradigms, which places a routing strategy at the heart of the decision-making process. The problem of planning the work of RTE was solved by considering the relationship of tactical and operational levels of decision-making. For this purpose, researchers designed the network promotion of material flow on the annual volume of production and delivery of products to consumers, the location of service facilities and distribution centres on the ground, the characteristics of transport services [2]. For the planning of freight transport on the transport network in North-West Europe, the paper [3] solved an optimisation problem, which involved determining the minimum and maximum levels of transport tariffs in the current planning according to the daily demand for transport. In [4], there is a proposal to apply the formation of freight transportation plans based on the created heuristic decision methods both in current planning and operational planning to respond to the occurrence of exogenous events. A.P. Sokolov and V.S. Syunev [5] performed timber transportation planning by synthesising operational planning, current planning and strategic planning based on solving the routing problem. A fair amount of research was devoted to the application of logistical methods to RTE planning.

The relationship between current and operational planning was studied in determining the required number of material handling equipment and rolling stock in a warehouse [6], the freight loading plan (SCLPD) in the steel logistics industry [7], freight transport costs in urban $[8,9,10]$ and intercity traffic $[11,12]$. The work of

\footnotetext{
*Corresponding author: trofimova_1s@mail.ru
} 
L.S. Trofimova, S.A. Borodulina [13] reveals the importance of planning for road transport in the context of its competitiveness and formation of demand for transportation in the region, however, our study substantially supplements the model with input parameters in this article.

N.A. Filippova [14] proposed a theoretical and methodological approach to current planning based on the application of risk theory methods to the performance of transportation by different modes of transport, considering the study of demand, conditions of freight transportation, defining the objectives of operational planning and forecasting. Since one of the indicators determining the output of rolling stock is the time for loading and unloading, researchers and practitioners have emphasised the determination of this indicator in current planning for rail and maritime freight transport [15, 16, 17]. M. Gaudioso, M.F. Monaco et al. [18] have developed a Lagrangian decomposition scheme for a structured integer linear problem model.

The variety of theoretical and methodological approaches to RTE work planning, with regard to the interrelation of operational and current work on freight transportation confirms the relevance of the conducted research. This also allows supplementing the existing approaches with its own new vision and possibilities of a new theoretical and methodological approach.

The study relies on a synthesis of methods used for operational planning and current planning of the operation of a road transport company; the theory of road freight transport; and the theory of maintenance of rolling stock. There are also methods of system analysis in describing the interrelationship between the performance of the RTE in operational and current planning.

\section{Results and discussion}

The theoretical significance of the work lies in the improvement of the current planning of RTE work, considering the interrelation of current and operational work in the transportation of goods. Planning must take into account the indicators affecting current performance and those identified in the operational performance of the RTE (Figure 1). The purpose of the RTE business is to make a profit, so the article uses methods based on the calculation of annual profit (formulas (1), (2)).

$$
\begin{aligned}
& F=\sum_{i=1}^{I} P_{i} \rightarrow \max , i=\overline{1, I} \\
& \Pi_{c i}=\sum_{t=0}^{4}\left(R_{i, t}-Z_{i, t}\right), t=\overline{0,4}
\end{aligned}
$$

where $F$ is the effect of the operation of RTE in freight transportation, rub.; $P_{i}$ is profit from fulfilling the conditions of the $i$-th freight transportation contract for the year, rub.; $R_{i, t}$ is the result from fulfilling the conditions of the $i$-th contract in the $t$-th quarter, rub.; $Z_{c i, t}$ are costs of the fulfilment of the conditions of the $i$ th contract in the $t$-th quarter, rub.

The result of the RTE's work is determined by the output and the freight transport tariff (formula (3)).

$$
R_{i, t}=\left(Q_{i} \cdot n\right) \cdot D_{i, t} \cdot C_{i, t}, i=\overline{1, I} ; t=\overline{0,4}
$$

$Q_{i}$ is the output per shift of the rolling stock to fulfil the conditions of $i$-th contract, $\mathrm{t}$; $n_{i}$ is the Boolean variable of the rolling stock assignment, considering the compliance with the diagnostic parameters after the passage of maintenance with the required values, $n=\overline{0,1}, n=\operatorname{int}(n)$; $D_{i, t}$ is the planned number of shifts of the rolling stock to fulfil the conditions of the $i$-th contract in the $t$-th quarter; $D_{i, t}=\operatorname{int}\left(D_{i, t}\right) ; C_{i, t}$ is the value of the tariff for freight transportation under the $i$-th contract in the $t$-th quarter, rub/t.

$$
Z_{c i, t}=\left(Q_{i} \cdot n\right) \cdot S_{i, t},
$$

where $S_{i, t}$ is the value of the cost of freight transportation under the $i$-th contract in the $t$-th quarter, rub/t.

Planning must take into account the indicators affecting current performance and those identified in the operational performance of the RTE (Figure 1). The work [19] has proved that modern economic conditions force managers to make managerial decisions aimed at ensuring the requirements for contract terms, considering the interrelation of freight transportation processes and performance of maintenance (MRO) of rolling stock. The functioning of an RTE is seen as a probabilistic process.

The application of probability theory and mathematical statistics methods made it possible to establish that the length of a load journey in the city and in intercity transportation is a probabilistic value for the current planning and its change is described by a lognormal distribution law. These probabilistic performance indicators have an impact on the output and mileage of the rolling stock, and on the labour input for MRO in the current mode (Figure 1). On-site observations of urban freight transport operations have revealed that average technical speed and loading and unloading times have an impact on output and mileage in operational mode [20]. The application of probability theory and mathematical statistics methods made it possible to determine the limits of the confidence intervals for the output and mileage. A fragment of the study of freight transportation by KAMAZ-4326 rolling stock (actual load $5 \mathrm{t}$; freight - bricks, concrete products; working time $-10 \mathrm{~h}$ ) is shown in Fig. 2. 


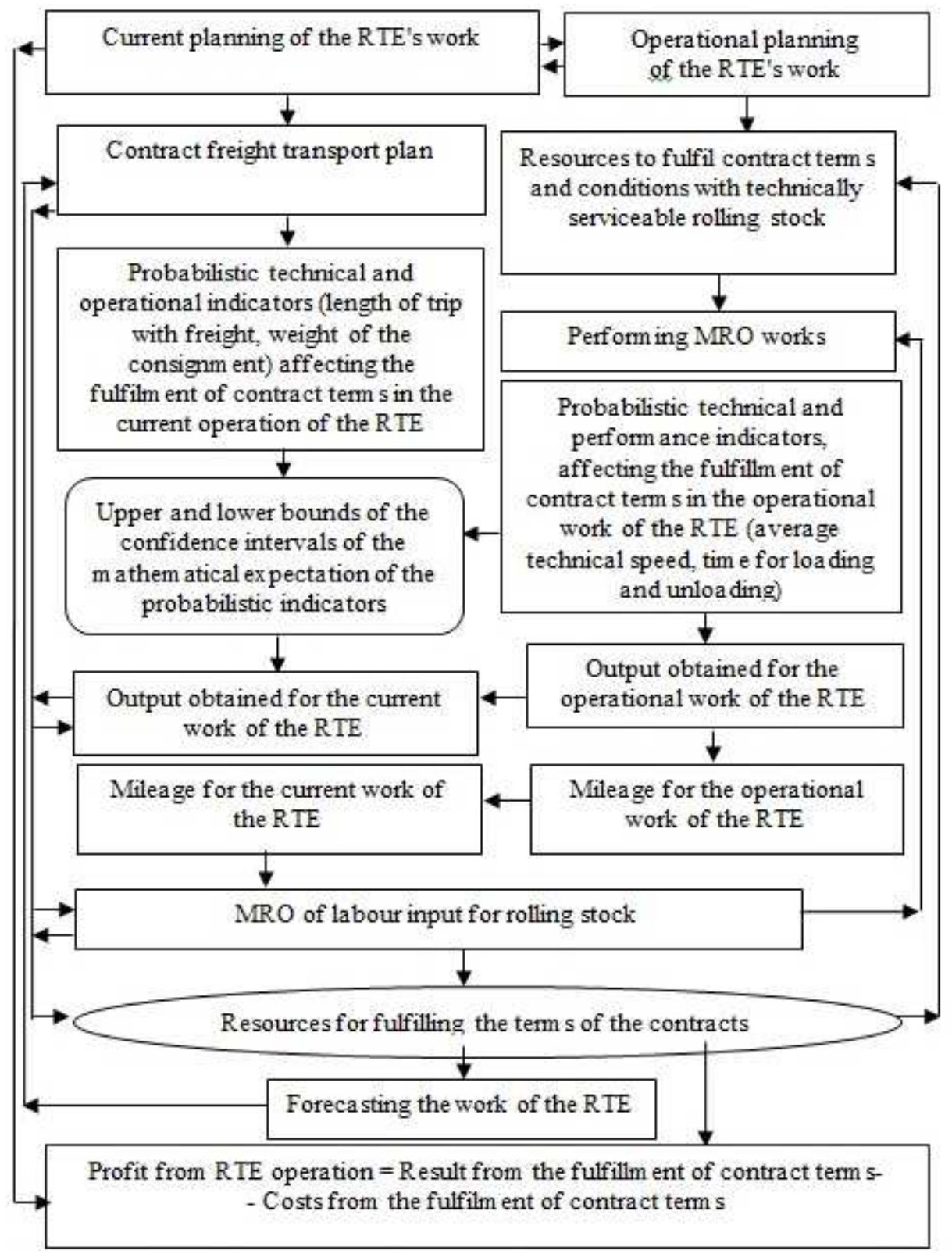

Figure 1. Interrelationship of planning indicators in the current and operational modes of the RTE's work

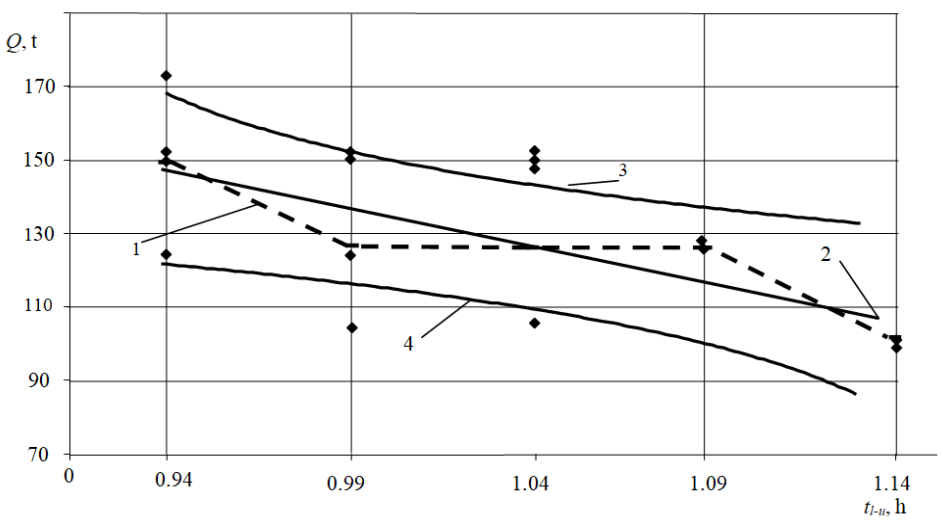

Figure 2. Dependence of influence of downtime for loading and unloading of KamAZ-4326 rolling stock on the output in tonnes during freight transportation in the city in operational mode: "•" - the actual value of output according to the photos of the working day; 1 - experimental regression line; 2 -the line that aligns the calculated experimental line;

3,4 - respectively, the upper and lower bounds of the confidence interval 
The output of the current planning process is a function of the probability indicators: length of journey with load, the weight of the consignment, average technical speed, loading and unloading time:

$$
Q_{i}=f\left(l_{2 e}, M_{o}, V_{T}, t_{n-p}\right)
$$

where $l_{z e} \mathrm{~s}$ the length of the journey with freight, $\mathrm{km} ; M_{o}$ is the mass of freight shipped, tonnes; $V_{T}$ is the average technical speed, $\mathrm{km} / \mathrm{h}$; tp-r is the time for loading and unloading, h.

Practical implementation of the developed theoretical and methodological approach to current planning will make it possible to determine the planned performance of RTE under the influence of probabilistic factors on current and operational work.

\section{Conclusions}

This paper presents a mathematical model that can be used to plan the work of the RTE, considering the relationship between current and operational work. The novelty of the research is associated with the identification of technical and operational indicators affecting the output and mileage of rolling stock in the operational and current modes of operation, as well as the development of methods to plan the work of RTE based on the relationship of indicators affecting the output and mileage in current and operational modes, describing a mathematical model that considers the functioning of RTE for freight transportation in the current and operational modes. The practical significance of the research results lies in the application of the mathematical model developed and the dependencies established, which will enable the development of a plan aimed at fulfilling the terms of the contracts and generating profits.

\section{References}

1. A. Quilliot, A. Sarbinowski, H. Toussaint, Annals of Operations Research. 298(1-2), 445-468, (2021). DOI: 10.1007/s10479-019-03497-4.

2. A.Y. Tyurin, Economics and Management of Innovation, 2, 97-111, (2017). DOI: 10.26730/2587-5574-2017-2-97-110.

3. B. Van Riessen, J. Mulder, R. R. Negenborn, R. Dekker, Flexible services and manufacturing journal. SEP 2020. DOI: 10.1007/s10696-02009394-4.

4. A. Soeanu, S. Ray, J. Berger, A. Boukhtouta, M. Debbabi, Expert systems with applications. 145. MAY 2020 DOI: 10.1016/j.eswa.2019.113099.

5. A.P. Sokolov, V.S. Syunev, Yu.V. Sukhanov, A.A. Seliverstov, Resources and Technology 13 (1), 1-22, (2016). DOI: 10.15393/j2.art.2016.3201.

6. N. V. Napkhonenko, M. R. Karaeva, Bulletin of the South Russian State Technical University
(Npi). 4, 91-98, (2019). DOI: 10.17213/20752067-2019-4-91-98.

7. J.Y. Liu, J.L. Mao, J.J. Liao, H.Q. Hu, Y. Guo, A.Y. Zhou, Ieee 36th international conference on data engineering, 1758-1761 (2020). DOI: 10.1109/ICDE48307.2020.00163.

8. A. O. Nesterov, L. Yu. Shevyrev, Trends in Science and Education, 50-2, 49-52, (2019). DOI: 10.18411/lj-05-2019-39.

9. A. P. Sokolov, V. S. Syunev, Yu. V. Sukhanov, A. A. Seliverstov, Resources andTechnology 11 (1), 50-65, (2014). DOI: 10.15393/j2.art.2014.2781.

10. C. Monardes-Concha, C. Serrano-Julio, C. Hoffmann, International transactions in operational research. DEC 2020 DOI: 10.1111/itor.12923.

11. N. Shramenko, D. Muzylyov, V. Shramenko, Advances in design, simulation and manufacturing III: manufacturing and materials engineering, Lecture Notes in Mechanical Engineering. 1, 201-209, (2020). DOI: 10.1007/978-3-030-50794-7_20/.

12. P. Wolff, S. Emde, H.-C. Pfohl, Internal resource requirements: The better performance metric for truck scheduling? (Omega, United Kingdom, 2021). DOI: 10.1016/j.omega.2021.102431.

13. L.S. Trofimova, S.A. Borodulina Bulletin of the Irkutsk State Technical University. 10 (129), 195205, (2017). DOI: 10.21285/1814-3520-2017-10195-205.

14. N. A. Filippova Automation and Control in Technical Systems. 3(11), 159-164, (2014). DOI: 10.12731/2306-1561-2014-3-15

15. I. G. Belozerova Proceedings of the St. Petersburg University of Railway Transport. Saint Petersburg, 16 (3), 372-379, (2019). DOI: 10.20295/1815-588X-2019-3-372-379.

16. E. I. Antonova, I. A. Vasiliev Operation of sea transport. 2, 3-8, (2019). DOI: 10.34046/aumsuomt91/1.

17. T.E. Smolentseva, A.V. Svishchev, Modeling, optimization and information technologies. 8(3), 1-9, (2020)9. DOI: 10.26102/23106018/2020.30.3.036.

18. M. Gaudioso, M. F. Monaco, M.A. Sammarra, Lagrangian heuristics for the truck scheduling problem in multi-door, multi-product CrossDocking with constant processing time. (Omega, United Kingdom, 2021). DOI: 10.1016/j.omega.2020.102255.

19. L. S. Trofimova, N. G. Pevnev Bulletin of SibADI. 6(58), 71-78, (2017). DOI: https://doi.org/10.26518/2071-7296-2017-6(58)63-71.

20. B. S. Trofimov, N. G. Pevnev Bulletin of the Ural State University of Railway Transport, 1 (33), 6269, (2017). DOI:10.20291/2079-0392-2017-1-6269. 